\title{
Management of nonsteroidal anti-inflammatory drug-induced gastroduodenal disease by acid suppression
}

\author{
R Lad MD FRCPC, D Armstrong MA MB BChir MRCPUK FRCPC
}

R Lad, D Armstrong. Management of nonsteroidal anti-inflammatory drug-induced gastroduodenal disease by acid suppression. Can J Gastroenterol 1999;13(2):135-142. One major cause of peptic ulceration is the use of nonsteroidal anti-inflammatory drugs (NSAIDs). The precise mechanisms through which NSAIDs cause peptic ulceration are unknown, but the discovery that they reduce the production of 'cytoprotective' prostaglandins led to the hypothesis that coadministration of exogenous prostaglandins heals and prevents NSAID-induced gastroduodenal ulcers and other mucosal lesions. Studies using high doses of misoprostol have shown that it does have a protective effect; however, gastrointestinal intolerance of this prostaglandin $E_{2}$ analogue is common. Early indications that acid suppression was effective in the management of NSAID-related peptic ulcers came from studies showing that gastric ulcers could be healed by omeprazole in patients who continued to take NSAIDs. Other studies suggested that acid suppression reduces the incidence of mucosal lesions but that standard dose ranitidine protects only against duodenal lesions. Subsequent studies reported that higher dose $\mathrm{H}_{2}$ receptor antagonist therapy can protect against both gastric and duodenal ulcers during continued NSAID therapy. An ideal therapeutic strategy would heal NSAID-related ulcers and prevent the development of new NSAID-related lesions and complications in patients who are unable to discontinue NSAID therapy. A number of recent studies indicate that effective acid-suppressive treatment with the proton pump inhibitor omeprazole can achieve these aims. Overall, data from recent studies show that acid suppression with the proton pump inhibitor omeprazole at a dose of $20 \mathrm{mg}$ daily is the most effective means of healing NSAID-associated gastroduodenal lesions and that it is the most effective prophylactic therapy. In the long run, the role of omeprazole will have to be evaluated with respect to its cost effectiveness compared with other strategies and with respect to the development of less damaging NSAIDs.

Key Words: Famotidine, Misoprostol, Nonsteroidal anti-inflammatory drugs, Omeprazole, Peptic ulcer, Ranitidine

\section{Le traitement de la maladie gastro-duodénale liée aux AINS par la suppression acide}

RÉSUMÉ : L'une des principales causes de l'ulcère gastro-duodénal est l'emploi d'anti-inflammatoires non stéroïdiens (AINS). Les mécanismes précis par lesquels les AINS provoquent l'ulcère gastro-duodénal nous échappent toujours, mais la découverte du fait qu'ils ralentissent la production des prostaglandines cytoprotectrices a conduit à l'hypothèse selon laquelle l'administration concomitante de prostaglandines exogènes permet de guérir et de prévenir les ulcères gastro-duodénaux provoqués par les AINS et d'autres lésions des muqueuses. Des études sur de fortes doses de misoprostol ont démontré qu'il exerce un effet protecteur. Par contre, l'intolérance gastro-intestinale à l'endroit de cet analogue des prostaglandines $\mathrm{E}_{2}$ est fréquente. Les premiers signes de l'efficacité de la suppression acide en traitment des ulcères gastro-duodénaux nous ont été fournis par des études dans le cadre desquelles des ulcères gastriques ont pu être guéris par l'oméprazole chez des patients qui continuaient de prendre des AINS. Selon d'autres études, la suppression acide réduit la fréquence des lésions muqueuses, mais la dose standard de ranitidine ne protège que contre les lésions duodénales. D'autres études ont par la suite fait état d'une protection conférée contre les ulcères gastriques et duodénaux par les anti- $\mathrm{H}_{2}$ à fortes doses pendant le traitement aux AINS. Une stratégie thérapeutique idéale serait de pouvoir guérir les ulcères provoqués par les AINS et prévenir l'installation des nouvelles lésions et complications dues aux AINS chez les patients qui ne peuvent pas se passer d'anti-inflammatoires. Un certain nombre d'études récentes indiquent qu'un traitement de suppression acide efficace au moyen de l'inhibiteur de la pompe à protons omép razole peut donner de tels résultats. De façon globale, les données tirées d'études récentes révèlent que la suppression acide au moyen de l'inhibiteur de la pompe à protons oméprazole à raison de $20 \mathrm{mg}$ par jour est la façon la plus efficace de faire cicatriser les lésions gastro-duodénales associées aux AINS et qu'il s'agit du traitement prophylactique le plus efficace. À longue échéance, le rôle de l'oméprazole devra être vérifié en ce qui a trait à sa rentabilité comparativement à d'autres stratégies et en ce qui a trait à la mise au point d'AINS moins dommageables.

Division of Gastroenterology, McMaster University, Hamilton, Ontario

Correspondence: Dr D Armstrong, HSC-4W8, Division of Gastroenterology, McMaster University Medical Centre, 1200 Main Street West, Hamilton, Ontario L8N 325. Telephone 905-521-2100 ext 6404, fax 905-521-5072, e-mail armstro@fhs.csu.mcmaster.ca 
$\mathrm{N}$ onsteroidal anti-inflammatory drugs (NSAIDs) are one of the most widely used medications, and some are now available over-the-counter. They are indicated for a variety of ailments, and their anti-inflammatory actions make them the cornerstone for management of chronic rheumatic and degenerative musculoskeletal disorders. However, these agents are associated with gastrointestinal toxicity ranging from mild dyspepsia to significant gastrointestinal bleeding or perforation, and death. Mechanisms of NSAID-induced gastrointestinal injury include direct toxicity to the mucosa and indirect inhibition of prostaglandin production via cyclo-oxygenase- 1 inhibition. It is estimated that $24 \%$ of serious gastrointestinal events related to peptic ulcer disease in the general population can be attributed to the use of NSAIDs (1).

The exact degree to which NSAIDs cause gastrointestinal complications varies. A number of meta-analyses and cohort studies on this subject found that NSAID users are at approximately two to four times greater relative risk than nonusers for development of bleeding or perforation, hospitalization, or death from NSAID-induced gastrointestinal events (2-4). The risk increases for the elderly, those on corticosteroids, those with a prior history of peptic ulcer disease, and those taking multiple or high dose NSAIDs. The risk of complications appears to be highest in the first month of use but continues at a constant rate thereafter. Individual agents such as azapropazone, tolmetin, piroxicam and ketoprofen carry the highest risks, with lower risks attributable to ibuprofen and diclofenac (5). Interpretation of these data is complicated by the fact that many patients who develop gastrointestinal complications, especially the elderly, are asymptomatic before the event. In addition, there is poor correlation among endoscopic damage, upper gastrointestinal symptoms and the occurrence of major bleeding.

A number of agents have been studied for both the treatment and prevention of NSAID-induced gastroduodenal ulceration. These include the prostaglandin analogue misoprostol, histamine $\mathrm{H}_{2}$ receptor antagonists $\left(\mathrm{H}_{2} \mathrm{RAs}\right)$ and proton pump inhibitors such as omeprazole. One of the most effective management strategies is to discontinue the NSAID in question; however, many patients require NSAIDs for ongoing control of pain and inflammation in place of or as an adjunct to more toxic or slower acting disease-modifying agents. The purpose of this review is to examine the literature to assess the role of acid-suppressing drugs in the treatment and prevention of NSAID-induced gastroduodenal ulceration.

\section{$\mathrm{H}_{2} \mathrm{RAs}$}

The role of $\mathrm{H}_{2} \mathrm{RAs}$ in the healing and prevention of NSAID-induced ulcers has been extensively studied. For patients who do develop ulceration secondary to NSAIDs, discontinuation of these agents can be problematic because alternative therapies may provide inferior control of pain and inflammation. In these cases, it may be preferable to continue NSAID therapy while using acid suppression to heal the ulcer. Lancaster-Smith et al (6) examined the effi- cacy of ranitidine in the healing of NSAID-induced gastric and duodenal ulcers and erosions, and compared healing rates in those who continued NSAID treatment with rates in those who did not. In this study, 211 patients with NSAIDinduced gastroduodenal ulceration were randomized to continue or discontinue NSAID treatment while starting ranitidine $150 \mathrm{mg}$ twice daily. The healing rates of gastric ulcers, confirmed endoscopically, in those who stopped using NSAIDs were $71 \%, 95 \%$ and $100 \%$ at four, eight and 12 weeks, respectively, compared with 54\%, 63\% and 79\% in those who continued NSAIDs. These differences were statistically significant at eight and 12 weeks. In those with duodenal ulcers, similar results were found, with healing rates for the group stopping NSAIDS of $74 \%, 100 \%$ and $100 \%$ at four, eight and 12 weeks, respectively, compared with $57 \%, 84 \%$ and $92 \%$ for the group continuing NSAIDs. These results were statistically significant at eight weeks due only to the high healing rates with ranitidine. Healing rates were faster for those with duodenal ulcers than for those with gastric ulcers on continued anti-inflammatory therapy. The high healing rates for those who discontinued NSAID therapy were comparable with healing rates for non-NSAIDassociated peptic ulcers treated with $\mathrm{H}_{2} \mathrm{RAs}$, suggesting that NSAID-induced ulcers are just as responsive to $\mathrm{H}_{2} \mathrm{RAs}$ after the NSAID has been withdrawn. Unfortunately, no placebo group of subjects, without ranitidine therapy, was included to examine the ulcer healing rates in those who simply discontinued use of NSAIDs. This study suggests that NSAIDinduced gastroduodenal ulceration can be treated effectively with ranitidine $150 \mathrm{mg}$ twice daily, even if NSAID use is continued. Although healing is slowed by continuation of the anti-inflammatory agent, substantial rates of healing can be achieved. Walan et al (7) reported comparable healing rates in those with NSAID-induced ulcers in a study of gastric ulcer patients who were randomized to high $(40 \mathrm{mg}$ daily) or low dose (20 mg daily) omeprazole, or ranitidine 150 mg twice daily while continuing NSAIDs. Gastric ulcer healing with ranitidine was $53 \%$ after eight weeks of therapy with continued NSAID use.

The use of famotidine, another $\mathrm{H}_{2} \mathrm{RA}$, was assessed by Hudson et al (8) in 1997. After long term NSAID therapy, rheumatic patients with NSAID-induced gastroduodenal ulcers were treated with open label famotidine $40 \mathrm{mg}$ twice daily for 12 weeks; 88 patients continued NSAIDs, while 16 discontinued them. At four weeks, the cumulative intention to treat healing rate was $65.9 \%$ for those continuing NSAIDs compared with $81.3 \%$ for those discontinuing them. At 12 weeks, healing rates rose to $89 \%$ in those who remained on NSAIDs compared with 100\% in those who discontinued them. Again, healing rates for duodenal ulcers were somewhat higher than those for gastric ulcers.

A number of trials have evaluated the use of prophylactic $\mathrm{H}_{2} \mathrm{RAs}$ in the prevention of gastroduodenal injury. In healthy volunteers taking short term, high dose acetylsalicylic acid (ASA), famotidine $20 \mathrm{mg}$ significantly decreased the rate of gastric microbleeding and antral hemorrhagic lesions (9). For patients receiving NSAIDs, cimetidine was 
one of the first $\mathrm{H}_{2} \mathrm{RAs}$ to be studied; however, no significant protective effect was found for the prevention of gastroduodenal ulceration in rheumatology patients $(10,11)$.

A large European multicentre, double-blinded, placebo controlled trial was conducted in a cohort of 297 rheumatoid and osteoarthritis patients who continued NSAIDs while using ranitidine $150 \mathrm{mg}$ twice daily for ulcer prophylaxis (12). Although no protective effect for gastric ulcers was found, there was a significant decrease in the number of duodenal ulcers at eight weeks in the ranitidine group compared with the placebo group (1.5\% versus $8 \%)$. Robinson et al (13) showed a similar protective effect on duodenal ulcers but no effect on gastric ulcers in an American population.

Famotidine prophylaxis has also been assessed over a longer period of time in chronic NSAID users. Rheumatic patients who had taken NSAIDs for over one month were randomized to high dose famotidine ( $40 \mathrm{mg}$ twice daily), low dose famotidine (20 mg twice daily) or placebo while NSAIDs were continued (14). They were reassessed endoscopically and with respect to symptoms after four, 12 and 24 weeks of therapy. After six months, there was a significant decrease in gastroduodenal ulceration in those treated with high and low dose famotidine compared with those who received placebo (10.8\% and $16.8 \%$ versus $28.7 \%$ ) (Figure 1). Compared with placebo, the higher dose of famotidine was associated with a lower incidence of both gastric and duodenal ulcers, whereas the lower dose was associated with a lower incidence of duodenal ulcers only. The prevalence of abdominal pain decreased from $30 \%$ at baseline to $19 \%$ after 24 weeks of famotidine but was unchanged in the placebo group. The famotidine was well tolerated; the main side effect was a small, but statistically significant decrease in platelet count.

In conjunction with the previously described trial of famotidine for ulcer healing, Hudson et al (8) investigated famotidine maintenance therapy over a period of six months in 78 patients who continued to use NSAIDs. In this doubleblind study, the patients were randomized to receive famotidine $40 \mathrm{mg}$ twice daily or placebo after their initial ulcers healed. There was a significant decrease in gastroduodenal ulceration at six months in those receiving famotidine compared with those receiving placebo (26\% versus $53.5 \%$ ), but the rate of ulcer occurrence was higher in patients who had prior confirmed ulceration than in patients who had not had prior ulceration (14) (Figure 1). When analyzed separately, the reduction in both gastric and duodenal ulceration was similar with high dose famotidine prophylaxis.

These studies demonstrate a protective effect of $\mathrm{H}_{2} \mathrm{RAs}$ primarily in the duodenum, supporting the theory that pathogenic and defence mechanisms in the duodenum may be different from those present in the stomach. $\mathrm{H}_{2} \mathrm{RAs}$ are useful in healing gastroduodenal ulcers for patients who discontinue NSAID therapy and for those who do not. Patients who continue NSAID therapy have slower rates of healing, but these rates are still relatively high. Low doses of $\mathrm{H}_{2} \mathrm{RAs}$ are effective in the prevention of duodenal ulcer, but higher doses are necessary for gastric ulcer prevention. It is possible that greater acid suppression is needed in the stomach than

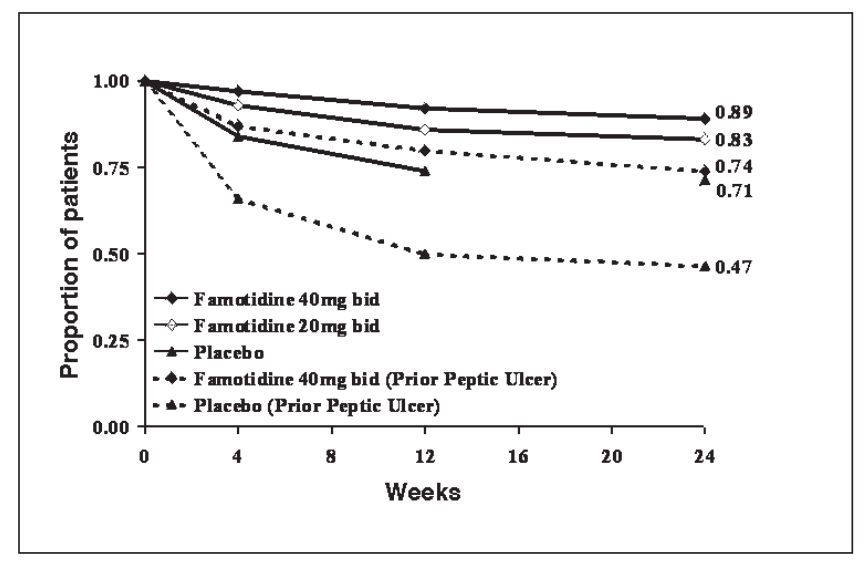

Figure 1) Proportions of patients remaining free of peptic ulceration on maintenance therapy with famotidine or placebo while nonsteroidal antiinflammatory drug therapy was continued. Patients without prior peptic ulceration were randomized to placebo, standard dose famotidine (20 mg bid) or high dose famotidine ( $40 \mathrm{mg}$ bid) for 24 weeks; in a parallel study, patients with prior peptic ulceration were randomized to placebo or high dose famotidine (40 $\mathrm{mg}$ bid). Data adapted from references 8 and 14

in the duodenum to minimize NSAID-mediated mucosal injury.

Some reports have suggested that the efficacy of $\mathrm{H}_{2} \mathrm{RAs}$ decreases after prolonged periods of treatment. For example, when gastric acidity was assessed at initiation, after eight days and after one month of $\mathrm{H}_{2} \mathrm{RA}$ therapy, the degree of reduction in gastric acidity was found to decrease over time, suggesting that a significant degree of tolerance results from continued $\mathrm{H}_{2} \mathrm{RA}$ therapy $(15,16)$. Thus, the prophylactic efficacy of $\mathrm{H}_{2} \mathrm{RA}$ therapy may be lower in the long term than would otherwise be expected from the results of standard, six-month follow-up studies.

\section{PROTON PUMP INHIBITORS}

Based on the above data showing that $\mathrm{H}_{2}$ RAs have a dosedependent effect in healing or preventing NSAID-related peptic ulcers, it seems plausible that increased acid suppression will result in faster and more effective healing of NSAID-induced ulcers. Natural candidate drugs for these effects are proton pump inhibitors, which block the final common pathway in acid secretion.

As was noted above, the early randomized, doubleblinded trial by Walan et al (7) showed significantly increased healing rates for all gastric ulcers with continued use of NSAIDs with omeprazole therapy compared with rates with ranitidine at both four and eight weeks. Healing at eight weeks was $82 \%$ for omeprazole $20 \mathrm{mg}$, $95 \%$ for omeprazole $40 \mathrm{mg}$ and $53 \%$ for ranitidine $150 \mathrm{mg}$ twice daily. Similar healing rates of $82 \%$ and $96 \%$ at four and eight weeks, respectively, have been demonstrated for both gastric and duodenal ulcers in those continuing NSAIDs with omeprazole $20 \mathrm{mg}$ daily, with a substantial benefit over sucralfate therapy (17).

More recently, the effect of omeprazole on ulcer healing has been compared with the effect of misoprostol. The Omeprazole versus Misoprostol for NSAID-induced Ulcer Man- 


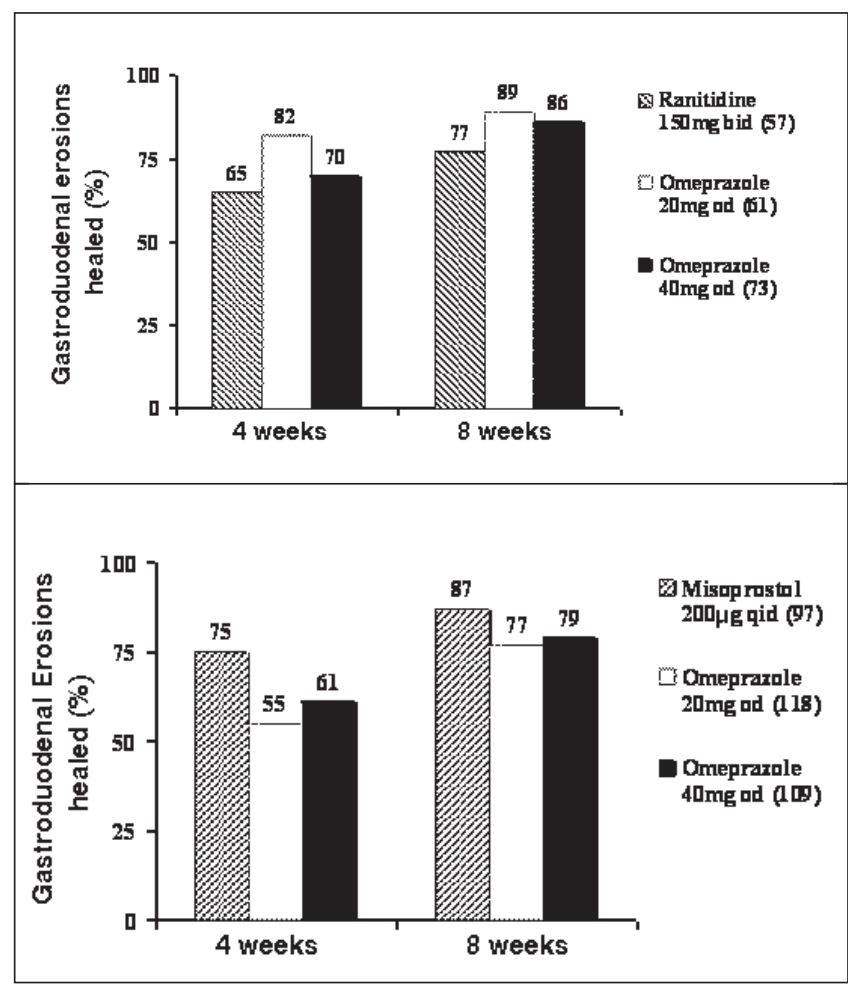

Figure 2) Percentage of gastroduodenal erosions healed after four and eight weeks in the Acid Suppression Trial: Ranitidine versus Omeprazole for NSAID-associated Ulcer Treatment (ASTRONAUT) (top) and the Omeprazole versus Misoprostol for NSAID-induced Ulcer Management (OMNIUM) (bottom) studies while nonsteroidal antiinflammatory drug (NSAID) therapy was continued. The legends indicate the number of patients in each treatment group. Data adapted from references 18 and 19

agement (OMNIUM) Study Group randomized 921 chronic NSAID users with gastroduodenal ulceration or 10 or more erosions to omeprazole $20 \mathrm{mg}$ daily, omeprazole $40 \mathrm{mg}$ daily or misoprostol $200 \mu \mathrm{g}$ four times daily while at least a minimum dose of their NSAIDs was continued (18). At eight weeks, the healing rates for gastric ulcers were significantly higher in those treated with omeprazole $20 \mathrm{mg}(87 \%)$ than in those given misoprostol (73\%). The healing rate with omeprazole $40 \mathrm{mg}$ was $80 \%$ but was not significantly different from that with misoprostol. The healing rates for duodenal ulcers were also significantly higher in the groups given omeprazole $20 \mathrm{mg}$ (93\%) or omeprazole $40 \mathrm{mg}$ (89\%) than in the group given misoprostol (77\%). In contrast, erosions healed significantly better during treatment with misoprostol $(87 \%)$ than with omeprazole $20 \mathrm{mg}(77 \%)$ or omeprazole $40 \mathrm{mg}$ (79\%) (Figure 2). This raises the issue of whether NSAID-induced erosions are distinct pathogenetically from NSAID-induced ulcers.

Omeprazole has also been compared with ranitidine for the healing of NSAID-induced ulcers during continued NSAID therapy. The Acid Suppression Trial: Ranitidine versus Omeprazole for NSAID-associated Ulcer Treatment (ASTRONAUT) Study Group randomized 541 chronic NSAID users with gastroduodenal ulcers (defined as a break of $3 \mathrm{~mm}$ or more) or 10 or more erosions to omeprazole $20 \mathrm{mg}$

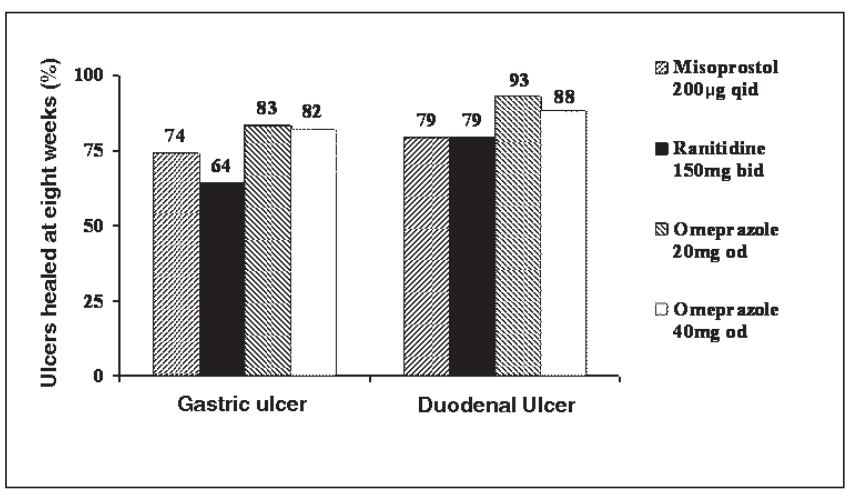

Figure 3) The percentage of gastric and duodenal ulcers healed after eight weeks while nonsteroidal anti-inflammatory drug (NSAID) therapy was continued. The percentage was calculated using pooled data from the Acid Suppression Trial: Ranitidine versus Omeprazole for NSAID-associated Ulcer Treatment (ASTRONAUT) and the Omeprazole versus Misoprostol for NSAID-induced Ulcer Management (OMNIUM) studies. The legends indicate the number of patients in each treatment group. Data adapted from references 18 and 19

daily, omeprazole $40 \mathrm{mg}$ daily or ranitidine $150 \mathrm{mg}$ twice daily for four to eight weeks depending on treatment success (19). The healing rates for gastric ulcers were significantly higher with omeprazole $20 \mathrm{mg}(84 \%)$ and omeprazole $40 \mathrm{mg}$ (86\%) than with ranitidine $(64 \%)$. The healing rates for duodenal ulcers were also higher with omeprazole $20 \mathrm{mg}$ (92\%) and omeprazole $40 \mathrm{mg}(88 \%)$ than with ranitidine $(81 \%)$. Erosions were significantly decreased in those treated with omeprazole compared with those receiving ranitidine (Figure 2). There was no significant difference between the two doses of omeprazole for the healing of gastric or duodenal ulcers or erosions. Overall, when the results of the OMNIUM and ASTRONAUT studies are pooled, the data indicate that misoprostol produced higher healing rates for gastric ulcers than did ranitidine although the two agents produced comparable healing rates for duodenal ulcers (Figure 3); however, omeprazole $20 \mathrm{mg}$ daily produced higher healing rates than either ranitidine or misoprostol for both gastric and duodenal ulcers. Dyspeptic symptoms were also better controlled by omeprazole $20 \mathrm{mg}$ daily than by either misoprostol or ranitidine (Table 1).

The incidence of moderate or severe adverse events during the healing phases of the OMNIUM and ASTRONAUT studies was greater for patients receiving misoprostol than for patients receiving ranitidine or omeprazole (Figure 4); differences were noted primarily for the occurrence of abdominal pain, diarrhea and flatulence, consistent with the gastrointestinal side effects of prostaglandin analogues reported previously in the literature $(20,21)$.

The protective effects of omeprazole on gastric microbleeding and endoscopic damage scores have been demonstrated in a number of studies of healthy controls taking short term ASA $(22,23)$. However, the prevention of mucosal injury in healthy volunteers does not provide incontrovertible evidence that the same treatment would prevent peptic ulceration or other sequelae in patients receiving NSAID therapy. The first large, randomized, double-blinded, 
TABLE 1

Resolution of dyspeptic symptoms with omeprazole, ranitidine and misoprostol therapy from the healing phases of the Acid Suppression Trial: Ranitidine versus Omeprazole for NSAID-associated Ulcer Treatment (ASTRONAUT) and Omeprazole versus Misoprostol for NSAID-induced Ulcer Management (OMNIUM) studies

Patients with moderate or severe symptoms (\%)

\begin{tabular}{lll} 
Therapy N $\quad$ Zero weeks & Four weeks \\
\hline
\end{tabular}

\section{ASTRONAUT study}

\section{Omeprazole $20 \mathrm{mg}$}

Ranitidine $150 \mathrm{mg}$ bid

174

174

52

50

$6.0^{*}$

OMNIUM study

\begin{tabular}{llll} 
Omeprazole $20 \mathrm{mg}$ & 308 & 45 & $6.0^{+}$ \\
Omeprazole $40 \mathrm{mg}$ & 315 & 45 & 11.0 \\
Misoprostol $200 \mu \mathrm{g}$ qid & 298 & 38 & 11.0 \\
\hline
\end{tabular}

$* P=0.04$ versus ranitidine; ${ }^{\dagger} P=0.004$ versus misoprostol. Data adapted from references 18 and 19

controlled trial to evaluate omeprazole prophylaxis in patients on long term NSAID therapy was the Nordic multicentre study (SCUR), published in 1996 (24). In this study, 177 patients with rheumatic disease requiring chronic NSAID therapy for at least three months were randomized to omeprazole $20 \mathrm{mg}$ daily or placebo for three months while at least a minimum dose of NSAID therapy was continued. Endoscopy and clinical assessment were performed after one and three months. Gastroduodenal ulceration occurred in $4.7 \%$ of omeprazole-treated patients compared with $16.7 \%$ of placebo-treated patients; $15.3 \%$ of those treated with omeprazole developed dyspeptic symptoms requiring active treatment compared with $35.6 \%$ of those on placebo.

It is interesting that there was no significant difference between the two treatment groups regarding the number of patients with more than 10 erosions in the stomach or duodenum but without ulcer. This brings into question the use of erosions as a surrogate marker for gastroduodenal damage. The high frequency of erosions in other studies may reflect damage done early in the course of NSAID treatment, whereas mucosal adaptation occurs with longer term exposure. When the data were assessed for all indices of recurrence including gastroduodenal ulcers, more than 10 erosions or worse than mild dyspeptic symptoms, there was a statistically significant difference, with recurrences occurring in $24.7 \%$ of the omeprazole group compared with $50 \%$ of the placebo group (Figure 5). However, the overall number of recurrent ulcers in this study was small, and this may explain the lack of statistical significance.

The Omeprazole versus Placebo as Prophylaxis against Ulcers or Erosions from NSAID Treatment (OPPULENT) study was conducted in 19 centres throughout Europe and the United states for long term NSAID users who had dys-

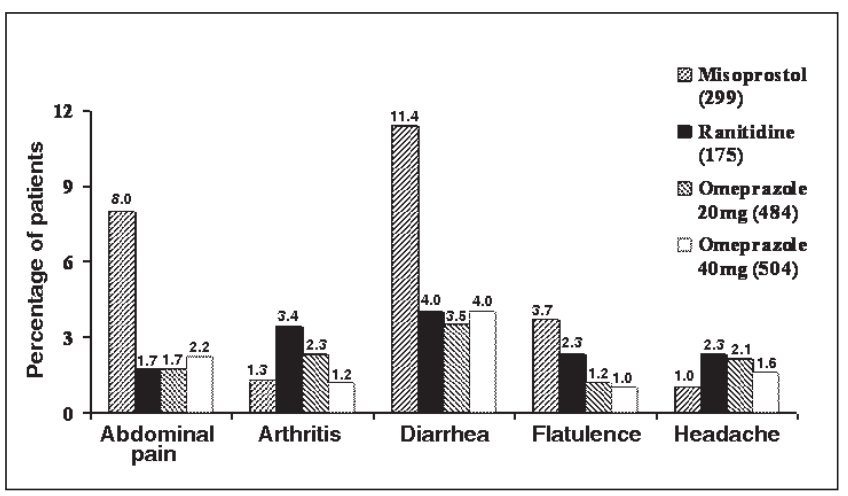

Figure 4) Pooled data from the Acid Suppression Trial: Ranitidine versus Omeprazole for NSAID-associated Ulcer Treatment and Ulcer Treatment (ASTRONAUT) and the Omeprazole versus Misoprostol for NSAID-induced Ulcer Management (OMNIUM) studies showing the percentage of moderate and severe adverse events during the initial, eight-week healing phases. The legends indicate the number of patients in each treatment group. Data adapted from references 18 and 19

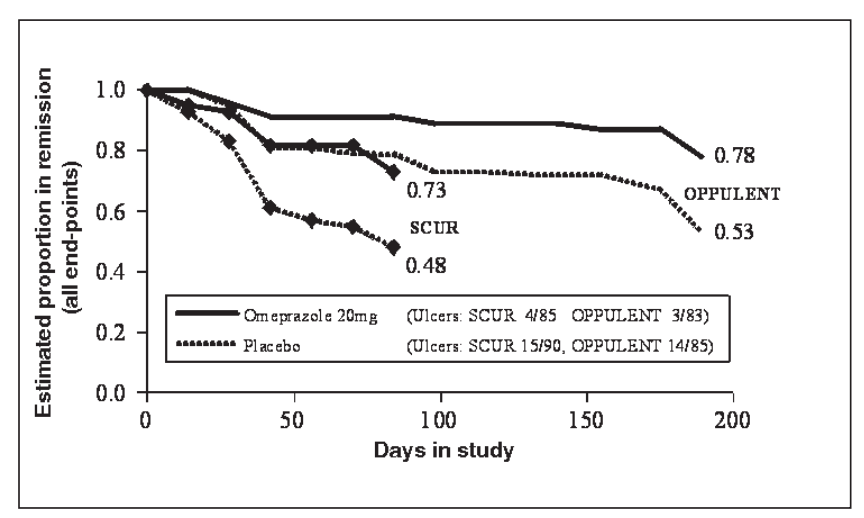

Figure 5) Estimated proportions of subjects in remission (less than 10 erosions, absent gastric or duodenal ulcer, mild or absent dyspeptic symptoms, or absence of adverse events) on maintenance therapy with omeprazole $20 \mathrm{mg}$ daily or placebo while NSAID therapy was continued (Nordic multicentre [SCUR], and Omeprazole versus Placebo as Prophylaxis against Ulcers or Erosions from NSAID Treatment [OPPULENT] studies). The legends indicate the number of patients in each treatment group who developed gastric or duodenal ulcers. Data adapted from references 24 and 25

peptic symptoms that were no worse than mild (25). Subjects who had no ulcers and no more than 10 gastric or duodenal erosions were randomized to omeprazole $20 \mathrm{mg}$ daily or placebo for six months with a follow-up endoscopy at one, three and six months or if symptoms recurred. End-points consistent with treatment failure were gastric or duodenal ulcers (more than $3 \mathrm{~mm}$ in diameter), more than 10 erosions in the stomach or duodenum, and dyspeptic symptoms sufficiently severe to require active treatment. The proportions of patients remaining in remission at six months were $64.7 \%$ for placebo and $81.9 \%$ for omeprazole. There was a significant increase in ulcers in the placebo arm (16.5\%) compared with the omeprazole treatment arm (3.6\%). The number of instances of multiple erosions and severe dyspeptic symptoms requiring treatment was similar. A number of variables were associated with a lower probability of treatment failure: 


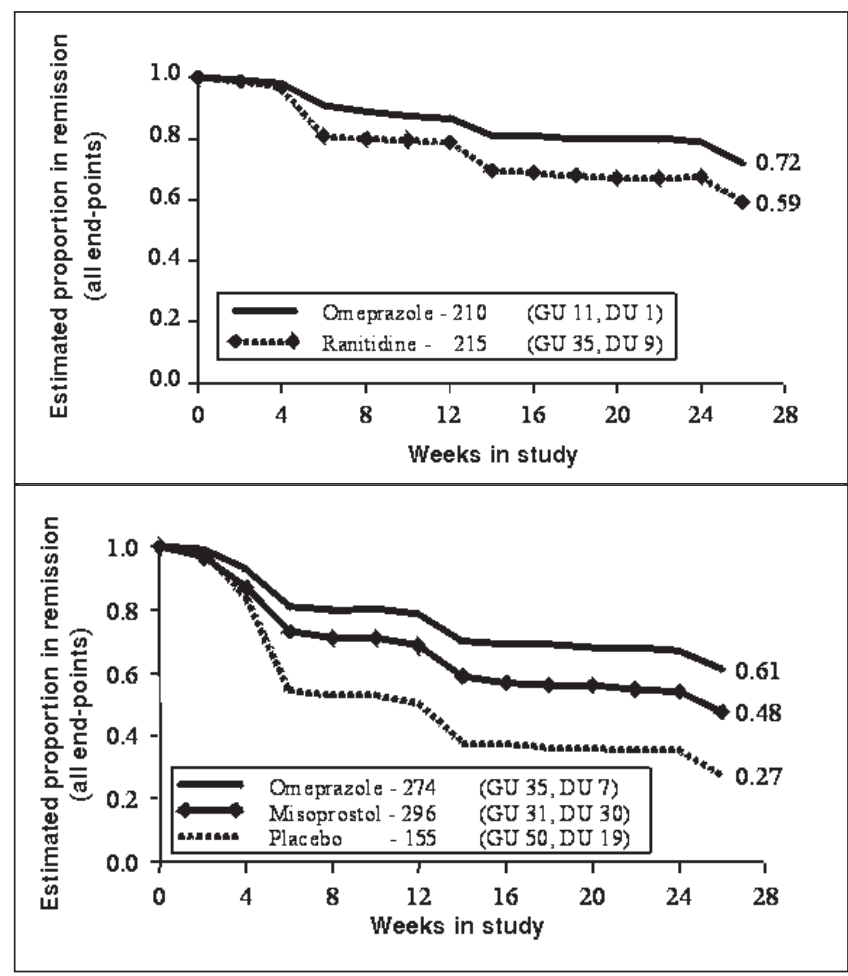

Figure 6) Estimated proportions of subjects in remission (fewer than 10 erosions, absent gastric [GU] or duodenal ulcer [DU], mild or absent dyspeptic symptoms, or absence of adverse events) on nonsteroidal antiinflammatory drug (NSAID) therapy and on maintenance therapy with omeprazole $20 \mathrm{mg}$ daily or ranitidine $150 \mathrm{mg}$ bid (Acid Suppression Trial: Ranitidine versus Omeprazole for NSAID-associated Ulcer Treatment study [ASTRONAUT] top) and omeprazole $20 \mathrm{mg}$ daily, misoprostol $200 \mu \mathrm{g}$ bid or placebo (Omeprazole versus Misoprostol for NSAID-Induced Ulcer Management study [OMNIUM] bottom). The legends indicate the number of patients in each treatment group and the number who developed gastric or duodenal ulcers. Data adapted from references 18 and 19

omeprazole therapy, having rheumatoid arthritis compared with osteoarthritis, and younger age. This study confirms that low dose omeprazole therapy is effective prophylaxis against NSAID-induced ulcers (Figure 5) although there were insufficient patients to determine whether omeprazole therapy would lead to a decrease in the number of clinically significant events.

The OMNIUM study group comparing omeprazole with misoprostol for ulcer healing was followed by a maintenance phase in which those with successful ulcer healing were randomized to omeprazole $20 \mathrm{mg}$ daily, misoprostol $200 \mu \mathrm{g}$ twice daily or placebo for six months (14). The primary end-points were the development of an ulcer, 10 or more gastric or duodenal erosions, moderate symptoms of dyspepsia or adverse events requiring discontinuation of treatment. At six months, the proportion of patients in remission was $61 \%$ of those on omeprazole, $48 \%$ of those on misoprostol and $27 \%$ of those on placebo (Figure 6). The incidences of gastric ulcers were $13 \%, 10 \%$ and $32 \%$ for those on omeprazole, misoprostol and placebo, respectively. The respective rates for duodenal ulcers were $3 \%, 10 \%$ and $12 \%$ at six months. Prognostic factors that were associated with a higher probability

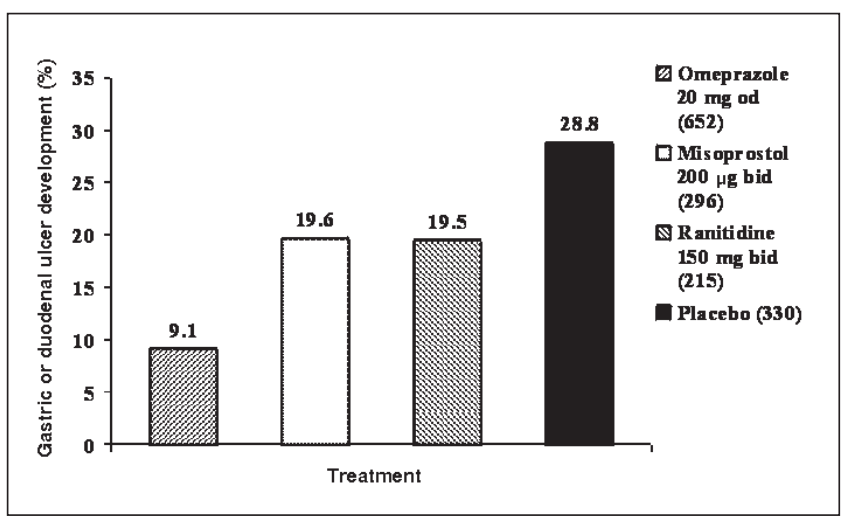

Figure 7) Pooled data from the Acid Suppression Trial: Ranitidine versus Omeprazole for NSAID-associated Ulcer Treatment (ASTRONAUT), Omeprazole versus Misoprostol for NSAID-Induced Ulcer Management (OMNIUM), Omeprazole versus Placebo as Prophylaxis against Ulcers or Erosions from NSAID Treatment (OPPULENT), and Nordic multicentre (SCUR) studies showing the overall rates of gastric or duodenal ulcer development during prophylactic therapy with omeprazole $20 \mathrm{mg}$ daily, misoprostol $200 \mu \mathrm{g}$ bid, ranitidine $150 \mathrm{mg}$ bid or placebo. The legends indicate the number of patients in each treatment group. Data adapted from references $18,19,24$ and 25

of remission were treatment with omeprazole rather than misoprostol, the presence of erosions alone at baseline, nonsmoking status and a positive test for Helicobacter pylori. Although misoprostol and omeprazole had similar prophylactic effects in preventing gastric ulceration, misoprostol was associated with a slightly higher incidence of adverse effects - primarily diarrhea - than omeprazole (59\% versus $48 \%$ ). Misorprostol was also associated with a higher incidence of medication discontinuation because of these adverse effects.

The ASTRONAUT study, comparing omeprazole with ranitidine for the healing of ulcers, also proceeded to a maintenance phase in which the 425 patients with healed ulcers who continued their NSAIDs were randomized to omeprazole $20 \mathrm{mg}$ daily or ranitidine $150 \mathrm{mg}$ twice daily for six months (19). At six months, $72 \%$ of the patients receiving omeprazole $20 \mathrm{mg}$ daily were in remission compared with $59 \%$ of the patients receiving ranitidine $150 \mathrm{mg}$ bid (Figure 6). The cumulative incidence of gastric ulcers was $5.2 \%$ in the omeprazole group compared with $16.3 \%$ in the ranitidine group; the corresponding rates for duodenal ulcers were $0.5 \%$ and $4.2 \%$.

When data from the four maintenance trials with omeprazole are pooled, the overall rate of ulcer occurrence at three $(22)$ to six $(18,19,25)$ months ranges from $9.1 \%$ for patients receiving omeprazole $20 \mathrm{mg}$ daily to $28.8 \%$ for patients who did not receive any prophylactic therapy, and misoprostol $200 \mu \mathrm{g}$ bid and ranitidine $150 \mathrm{mg}$ bid are associated with comparable ulcer rates of about 20\% (Figure 7).

Clearly, omeprazole therapy has a significant effect on NSAID-induced ulcer healing and prevention. In both high and low doses, it is superior to ranitidine in ulcer healing, with quicker healing. Low doses are superior to misoprostol and sucralfate (17). Omeprazole also substantially decreases 
the incidence of new gastric and duodenal ulceration in those who continue to take NSAIDs in the long term. It is, therefore, the agent of choice in high risk patients who must continue NSAID therapy, but its use is limited by cost.

\section{CONCLUSIONS}

There is a large body of evidence pertinent to the role of acid suppression therapy in the treatment and prevention of NSAID-induced gastroduodenal ulceration. Ideally, therapy should be based on discontinuation of the offending NSAID; however, this is often not possible. Although most studies are controlled, randomized trials, they are limited by variability in a number of factors such as NSAID dose, duration and type of agent. Control for these variables is difficult and may be considered unethical. Another limitation is the use of different definitions of an ulcer based on size and the use of erosions as a surrogate marker. The lack of data on clinically significant end-points such as significant gastrointestinal bleeding or perforation, or death means that whether the prevention of gastroduodenal lesions and symptoms reduces the incidence of severe NSAID-related complications cannot be asserted unequivocally. Pooled data from the four maintenance trials indicate that significant complications were noted in one of 654 patients who received omeprazole $20 \mathrm{mg}$ daily and two of the 331 patients who received placebo $(18,19,24,25)$, and, despite the relatively large numbers of patients enrolled in these four trials, this difference was not statistically significant. However, in the absence of very large multicentre trials with longer follow-up periods of one to two years or more, it is reasonable to assume that a reduced incidence of NSAID-related peptic ulcers would lead to a reduced complication rate.

Overall, the data suggest that there is an important role for acid suppression in the treatment and prevention of NSAID-induced ulceration. $\mathrm{H}_{2}$ RAs heal NSAID-related ulcers, even when NSAID use is continued; ranitidine and famotidine are comparable in efficacy, but healing, particularly of gastric ulcers, may take eight to 12 weeks. Famotidine is more effective at higher doses, suggesting that acid suppression is important in the healing of NSAID-related lesions; this is borne out by the finding that omeprazole heals NSAID-induced gastroduodenal ulcers more quickly than $\mathrm{H}_{2}$ RAs. Both omeprazole and $\mathrm{H}_{2}$ RAs are useful in the prevention of ulcers in those who continue NSAID therapy; ranitidine appears to be beneficial in the prevention of duodenal ulcers, but its role in prevention of gastric ulcers is less well established. However, famotidine, at higher doses, is useful for the prevention of both gastric and duodenal ulcers, suggesting that acid suppression is important also for the prevention of NSAID-related gastroduodenal lesions. This is supported by the finding that omeprazole is superior to $\mathrm{H}_{2} \mathrm{RAs}$ for the prevention of NSAID-induced gastroduodenal ulcers. In this regard, the treatment of NSAID-related ulcers appears to be similar to that of all peptic ulcers; metaanalyses have shown that healing rates for both duodenal (26) and gastric (27) ulcers are proportional to the degree of acid suppression produced by the healing agent, and, for pre- sumed NSAID-unrelated ulcers, this held true for enprostil, the only prostaglandin analogue for which acid suppression data were available. The only discrepant data regarding the importance of acid suppression for the treatment of NSAIDrelated ulcers, therefore, are that misoprostol appears to have healing and prophylactic effects in excess of those that would have been expected solely on the basis of its ability to inhibit gastric acid secretion.

There are, clearly, a number of unresolved issues that must be addressed with respect to the routine use of acidsuppressing drugs for people taking NSAIDs. Data available are derived from studies in which patients have taken standard NSAIDs and ASA; however, with the imminent availability of more specific cyclo-oxygenase- 2 inhibitors $(28,29)$ and the development of nitric oxide-releasing NSAIDs, which produce local release of vasoactive nitric oxide $(30,31)$, it is possible that newer NSAIDs will be associated with a much lower incidence of gastroduodenal mucosal damage and subsequent complications. However, these newer NSAIDs are likely to be more expensive than current NSAIDs, and, although proton pump inhibitors are relatively costly, the cost effectiveness of omeprazole therapy in Canada compared with other management strategies has yet to be evaluated.

The role of $H$ pylori eradication in the management of NSAID-related ulcers remains exceedingly controversial (32). H pylori does not appear to confer any additional risk of ulceration in patients taking NSAIDs, but, because $H$ pylori and NSAIDs appear to cause peptic ulceration by independent mechanisms, it seems reasonable to avoid the risk posed by $H$ pylori by curing the infection in patients who must continue NSAID therapy $(33,34)$. However, data from the ASTRONAUT and OMNIUM studies suggest that patients who are $H$ pylori-infected are less likely to relapse. Surprising as this observation may seem, it is consistent with reports that eradication of $H$ pylori may decrease the effect of omeprazole in suppressing gastric acidity. The recent studies $(17-19,24,25,35-37)$ show clearly that acid suppression is effective for the management of NSAID-related gastroduodenal disease; thus, any intervention - such as cure of $\mathrm{H}$ pylori that reduces the efficacy of acid-suppressing medication may be expected to produce a corresponding reduction in the prophylactic efficacy of acid suppression.

\section{REFERENCES}

1. Kurata JH, Nogawa AN. Meta-analysis of risk factors for peptic ulcer. Nonsteroidal antiinflammatory drugs, Helicobacter pylori, and smoking. J Clin Gastroenterol 1997;24:2-17.

2. Singh G, Ramey DR, Morfeld D, Shi H, Hatoum HT, Fries JF.

Gastrointestinal tract complications of nonsteroidal antiinflammatory drug treatment in rheumatoid arthritis. A prospective observational cohort study. Arch Intern Med 1996;156:1530-6.

3. Gabriel SE, Jaakkimainen L, Bombardier C. Risk for serious gastrointestinal complications related to use of nonsteroidal antiinflammatory drugs. A meta-analysis. Ann Intern Med $1991 ; 115: 787.96$

4. Griffin MR, Piper JM, Daugherty JR, Snowden M, Ray LA. Nonsteroidal anti-inflammatory drug use and increased risk for peptic ulcer disease in elderly persons. Ann Intern Med 1991;114:257-63.

5. Henry D, Lim LLY, Garcia Rodriguez LA, et al. Variability in risk of gastrointestinal complications with individual non-steroidal anti-inflammatory drugs: results of a collaborative meta-analysis. BMJ $1996+312: 1563-6$ 
6. Lancaster-Smith MI, Jaderberg ME, Jackson DA. Ranitidine in the treatment of non-steroidal anti-inflammatory drug associated gastric and duodenal ulcers. Gut 1991;32:252-5.

7. Walan A, Bader JP, Classen M, et al. Effect of omeprazole and ranitidine on ulcer healing and relapse rates in patients with benign gastric ulcer. N Engl J Med 1989;320:69-75.

8. Hudson N, Taha AS, Russell RI, et al. Famotidine for healing and maintenance in nonsteroidal anti-inflammatory drug-associated gastroduodenal ulceration. Gastroenterology 1997;112:1817-22.

9. Daneshmend TK, Prichard PJ, Bhaskar NK, Millns PJ, Hawkey CJ. Use of microbleeding and an ultrathin endoscope to assess gastric mucosal protection by famotidine. Gastroenterology 1989;97:944-9.

10. Roth SH, Bennett RE, Mitchell CS, Hartman RJ. Cimetidine therapy in nonsteroidal antiinflammatory drug gastropathy. Double-blind long-term evaluation. Arch Intern Med 1987;147:1798-801.

11. Davies J, Collins AJ, Dixon SA. The influence of cimetidine on peptic ulcer in patients with arthritis taking anti-inflammatory drugs. Br J Rheumatol 1986;25:54-8.

12. Ehsanullah RSB, Page MC, Tildesley G, Wood JR. Prevention of gastroduodenal damage induced by non-steroidal anti-inflammatory drugs: controlled trial of ranitidine. BMJ 1988;297:1017-21.

13. Robinson MG, Griffin JW Jr, Bowers J, et al. Effect of ranitidine gastroduodenal mucosal damage induced by nonsteroidal antiinflammatory drugs. Dig Dis Sci 1989;34:424-8.

14. Taha AS, Hudson N, Hawkey CJ, et al. Famotidine for the prevention of gastric and duodenal ulcers caused by nonsteroidal antiinflammatory drugs. N Engl J Med 1996;334:1435-9.

15. Nwokolo CU, Smith JT, Gavey C, Sawyerr A, Pounder RE. Tolerance during 29 days of conventional dosing with cimetidine, nizatidine, famotidine or ranitidine. Aliment Pharmacol Ther 1990;4(Supp1 1): 29.45 .

16. Smith JT, Gavey C, Nwokolo CU, Pounder RE. Tolerance during 8 days of high-dose $\mathrm{H}_{2}$-blockade: placebo-controlled studies of 24-hour acidity and gastrin. Aliment Pharmacol Ther 1990;4(Suppl 1):47-63.

17. Bianchi Porro G, Lazzaroni M, Manzionna G, Petrillo M. Omeprazole and sucralfate in the treatment of NSAID-induced gastric and duodenal ulcer. Aliment Pharmacol Ther 1998;12:355-60.

18. Hawkey CJ, Karrasch JA, Szczepanski L, et al. Omeprazole compared with misoprostol for ulcers associated with nonsteroidal antiinflammatory drugs. Omeprazole versus $M$ isoprostol for NSAID-induced Ulcer Management (OMNIUM) Study Group. $\mathrm{N}$ Engl J Med 1998;338:727-34.

19. Yeomans ND, Tulassay Z, Juhasz L, et al. A comparison of omeprazole with ranitidine for ulcers associated with nonsteroidal antiinflammatory drugs. Acid Suppression Trial: Ranitidine versus Omeprazole for NSAID-associated Ulcer Treatment

(ASTRONAUT) Study Group. N Engl J Med 1998;338:719-26.

20. Silverstein FE, Graham DY, Senior JR, et al. Misoprostol reduces serious gastrointestinal complications in patients with rheumatoid arthritis receiving nonsteroidal anti-inflammatory drugs. A randomized, double-blind, placebo-controlled trial. Ann Intern Med 1995;123:241-9.
21. Elliott SL, Yeomans ND, Buchanan RR, Smallwood RA. Efficacy of 12 months' misoprostol as prophylax is against NSAID-induced gastric ulcers. A placebo-controlled trial. Scand J Rheumatol 1994:23:171-6.

22. Daneshmend TK, Stein AG, Bhaskar NK, Hawkey CJ. Abolition by omeprazole of aspirin induced gastric mucosal injury in man. Gut $1990 ; 31: 514-7$.

23. Scheiman JM, Behler EM, Loeffler KM, Elta GH. Omeprazole ameliorates aspirin-induced gastroduodenal injury. Dig Dis Sci $1994,39: 97-103$.

24. Ekstrom P, Carling L, Wetterhus S, et al. Prevention of peptic ulcer and dyspeptic symptoms with omeprazole in patients receiving continuous non-steroidal anti-inflammatory drug therapy. A Nordic multicentre study. Scand J Gastroenterol 1996;31:753-8.

25. Cullen D, Bardhan KD, Eisner M, et al. Primary gastroduodenal prophylaxis with omeprazole for non-steroidal anti-inflammatory drug users. Aliment Pharmacol Ther 1998;12:135-40.

26. Jones DB, Howden CW, Burget DW, Kerr GD, Hunt RH. Acid suppression in duodenal ulcer: a meta-analysis to define optimal dosing with antisecretory drugs. Gut 1987;28:1120-7.

27. Howden CW, Hunt RH. The relationship between suppression of acidity and gastric ulcer healing rates. Aliment Pharmacol Ther $1990 ; 4: 25-33$.

28. Vane JR, Botting RM. Mechan ism of action of nonsteroidal antiinflammatory drugs. Am J Med 1998;104(Supp1 3A):2S.8S.

29. Schmassmann A. Mechanisms of ulcer healing and effects of nonsteroidal anti-inflammatory drugs. Am J Med 1998;104(Supp1 3A):43S-51S.

30. Wallace JL, Pittman QJ, Cirino G. Nitric oxide-releasing NSAIDS: a novel class of GI-sparing anti-inflammatory drugs. Agents Actions Suppl 1995;46:121-9.

31. Muscara MN, McKnight W, Del Soldato P, Wallace JL. Effect of a nitric oxide-releasing naproxen derivative on hypertension and gastric damage induced by chronic nitric oxide inhibition in the rat. Life Sci $1998 ; 62:$ PL235-40.

32. Malfertheiner P, Labenz J. Does Helicobacter pylori status affect nonsteroidal antiinflammatory drug-associated gastroduodenal pathology? Am J Med 1998;104(Suppl 3A):35S-40S.

33. Hunt RH, Thomson AB. Canadian Helicobacter pylori consensus conference. Canadian Association of Gastroenterology. Can J Gastroenterol 1998;12:31-42.

34. Current European concepts in the management of Helicobacter pylori infection. The Maastricht Consensus Report. European Helicobacter Pylori Study Group. Gut 1997;41:8-13.

35. Labenz J, Tillenburg B, Peitz U, et al. Helicobacter pylori augments the $\mathrm{pH}$-increasing effect of omeprazole in patients with duodenal ulcer. Gastroenterology 1996;110:725-32.

36. Verdú EF, Armstrong D, Fraser R, et al. Effect of Helicobacter pylori status on intragastric $\mathrm{pH}$ during treatment with omeprazole. Gut $1995 ; 36: 539-43$.

37. Verdú EF, Armstrong D, Idström JP, et al. Effect of curing Helicobacter pylori infection on intragastric $\mathrm{pH}$ during treatment with omeprazole. Gut $1995 ; 37: 743-8$. 


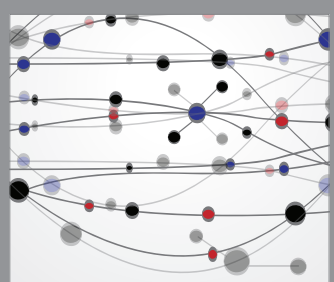

The Scientific World Journal
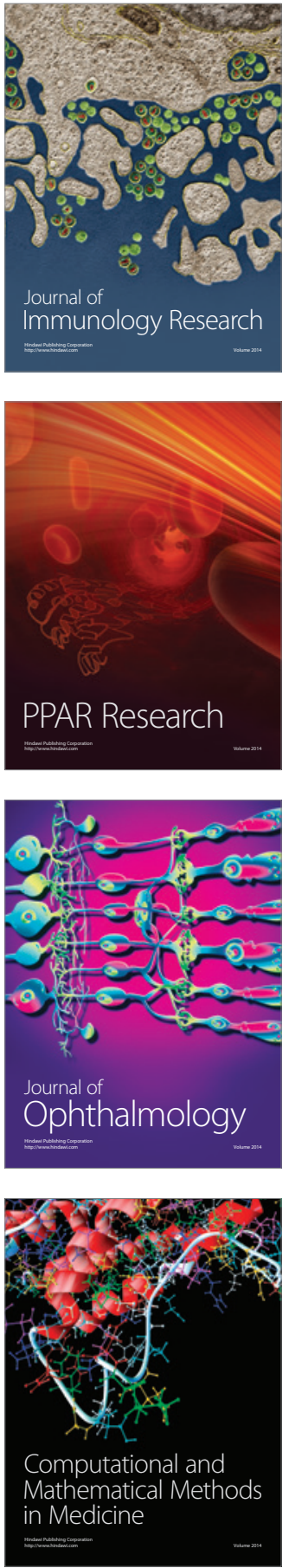

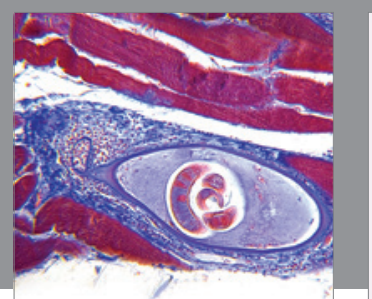

Gastroenterology Research and Practice

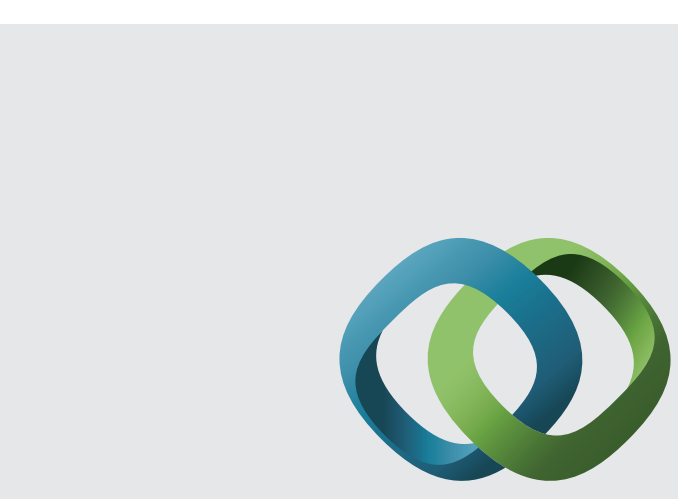

\section{Hindawi}

Submit your manuscripts at

http://www.hindawi.com
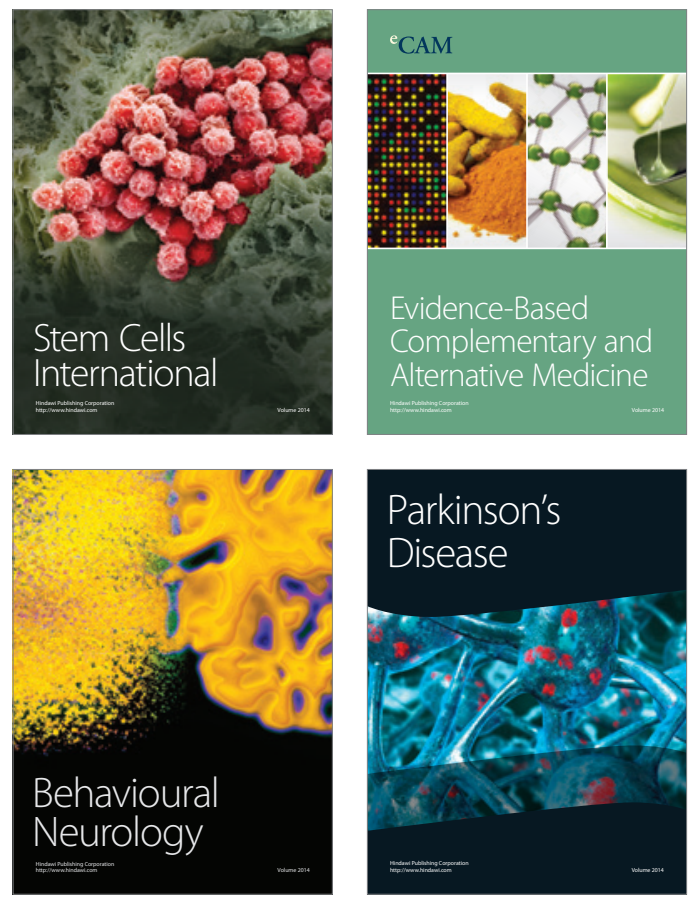
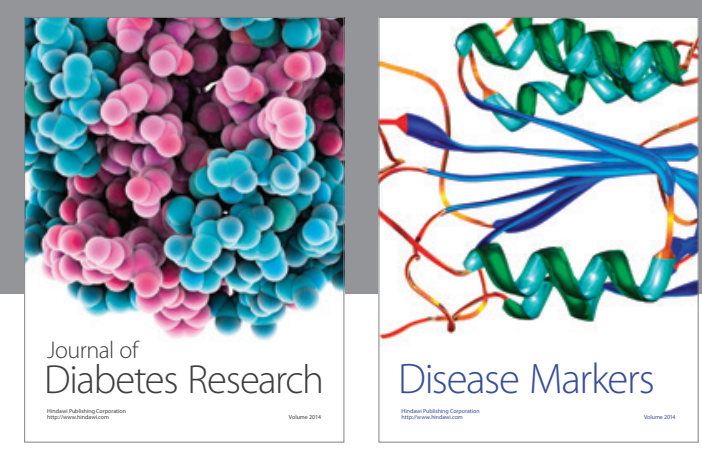

Disease Markers
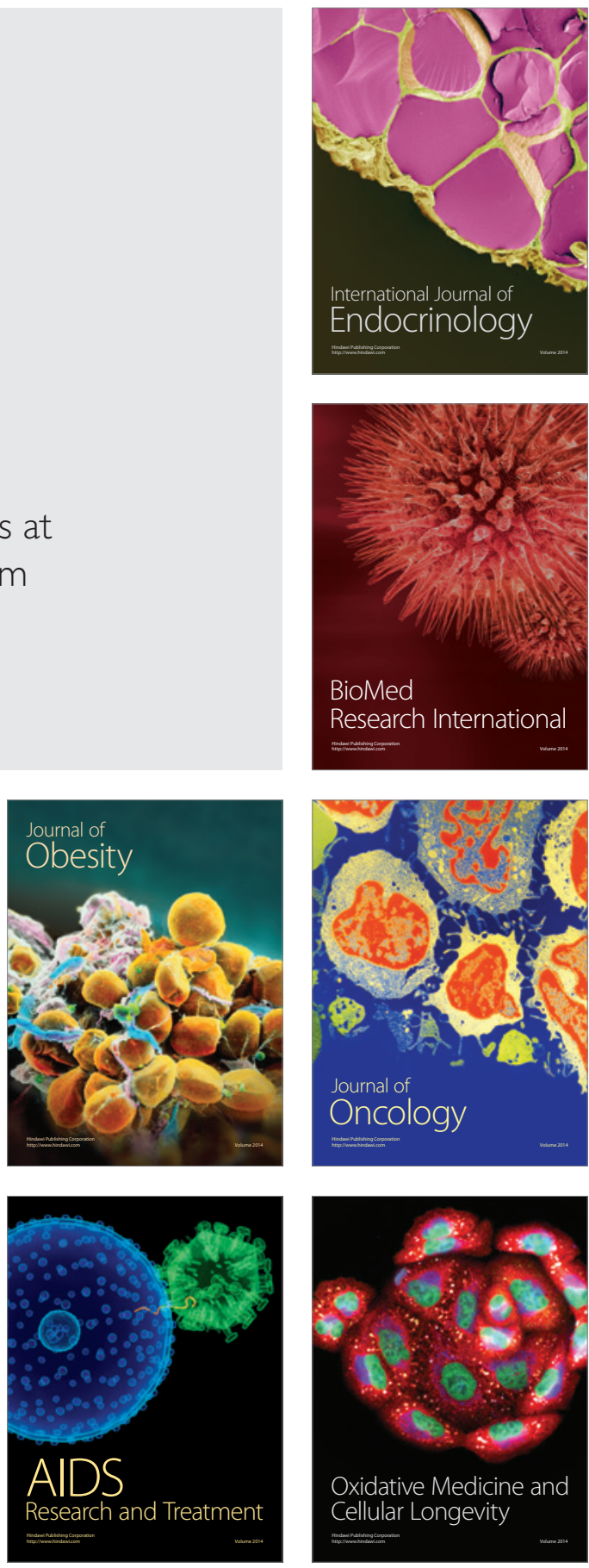